\title{
BI open Opportunistic pathology-based
screening for diabetes
}

Aaron J Simpson, ${ }^{1,2}$ Renata Krowka, ${ }^{1}$ Jennifer L Kerrigan, ${ }^{1}$ Emma K Southcott, ${ }^{1,3}$ J Dennis Wilson, ${ }^{2,3}$ Julia M Potter, ${ }^{1,3}$ Christopher J Nolan, ${ }^{2,3}$ Peter E Hickman ${ }^{1,3}$

To cite: Simpson AJ, Krowka R, Kerrigan JL, et al. Opportunistic pathologybased screening for diabetes. BMJ Open 2013;3:e003411. doi:10.1136/bmjopen-2013003411

- Prepublication history for this paper is available online. To view these files please visit the journal online (http://dx.doi.org/10.1136/ bmjopen-2013-003411).

Received 15 June 2013 Revised 10 August 2013 Accepted 12 August 2013

${ }^{1}$ Department of Chemical Pathology, The Canberra Hospital, Canberra, Australian Capital Territory, Australia

2Department of

Endocrinology, The Canberra Hospital, Canberra, Australian Capital Territory, Australia ${ }^{3}$ Australian National University Medical School, Canberra, Australian Capital Territory, Australia

Correspondence to Dr Christopher J Nolan; christopher.nolan@anu.edu. $\mathrm{au}$

\begin{abstract}
Objective: To determine the potential of opportunistic glycated haemoglobin $(\mathrm{HbA} 1 \mathrm{c})$ testing of pathology samples to detect previously unknown diabetes.

Design: Pathology samples from participants collected for other reasons and suitable for $\mathrm{HbA1c}$ testing were utilised for opportunistic diabetes screening. HbA1c was measured with a Biorad Variant II turbo analyser and $\mathrm{HbA} 1 \mathrm{c}$ levels of $\geq 6.5 \%$ (48 $\mathrm{mmol} / \mathrm{mol}$ ) were considered diagnostic for diabetes. Confirmation of previously unknown diabetes status was obtained by a review of hospital medical records and phone calls to general practitioners.
\end{abstract}

Setting: Hospital pathology laboratory receiving samples from hospital-based and community-based (CB) settings.

Participants: Participants were identified based on the blood sample collection location in the $\mathrm{CB}$, emergency department (ED) and inpatient (IP) groups. Exclusions pretesting were made based on the electronic patient history of: age $<18$ years, previous diabetes diagnosis, query for diabetes status in the past 12 months, evidence of pregnancy and sample collected postsurgery or transfusion. Only one sample per individual participant was tested.

Results: Of the 22396 blood samples collected, 4505 (1142 CB, 1113 ED, 2250 IP) were tested of which $327(7.3 \%)$ had $\mathrm{HbA} 1 \mathrm{c}$ levels $\geq 6.5 \%(48 \mathrm{mmol} / \mathrm{mol})$. Of these $120(2.7 \%)$ were determined to have previously unknown diabetes $(11$ (1\%) CB, 21 (1.9\%) $\mathrm{ED}, 88(3.9 \%)$ IP). The prevalence of previously unknown diabetes was substantially higher (5.4\%) in hospital-based (ED and IP) participants aged over 54 years.

Conclusions: Opportunistic testing of referred pathology samples can be an effective method of screening for diabetes, especially in hospital-based and older persons.

\section{INTRODUCTION}

Diabetes is an important and common disease with significant morbidity and mortality. ${ }^{1}$ Its worldwide prevalence in 2010 was estimated to be 285 million, and this was expected to increase to 439 million in $2030 .^{2}$ More than $90 \%$ of those affected have type 2 diabetes. $^{1}$ In 2000 in Australia, the

\section{ARTICLE SUMMARY}

Strengths and limitations of this study

- The strengths of this work are the large sample size, the inclusion of separate community-based, emergency department and inpatient groups, and the rigourous methodology used to confirm which subjects screening positive for diabetes truly had previously unknown diabetes.

- A limitation of the study is that the design did not allow for follow-up of outcomes for those subjects identified with previously unknown diabetes after general practitioner notification of the positive opportunistic HbA1c screening result.

prevalence of diabetes in persons $\geq 25$ years old was $7.5 \%$, and importantly, half of those with diabetes had not been diagnosed prior to the survey. ${ }^{3}$

The high prevalence of undiagnosed type 2 diabetes is due to the insidious nature of its onset. The delay in clinical diagnosis of type 2 diabetes has been estimated to be at least 5-7 years. ${ }^{4}$ This is of clinical relevance as microvascular and macrovascular complications are often already present at the time of diagnosis. ${ }^{4-6}$ As the association between hyperglycaemia and the development of retinopathy is very strong, the presence of this complication at the time of diabetes diagnosis is very likely a consequence of the prior undiagnosed diabetes. ${ }^{7}$ Even though hyperglycaemia is associated with a greater risk of macrovascular disease events, the causative role of hyperglycaemia in these complications is less clear. ${ }^{8}{ }^{9}$ Nevertheless, the UK Prospective Diabetes Study showed that better glycaemic control in type 2 diabetes patients over 10 years reduced microvascular complication rates and, with longer term follow-up, macrovascular events and death from any cause. ${ }^{10} 11$ Thus, early detection and treatment of type 2 diabetes has the potential to significantly reduce the morbidity and mortality associated with this disease. However, there has been recent debate relating to the cost-benefit analysis of diabetes 
screening versus population-based health promotion approaches to reduce risk. ${ }^{12} 13$

Recently, WHO, the American Diabetes Association (ADA) and the National Health Scheme in the UK endorsed the use of glycated haemoglobin (HbAlc) for the diagnosis of diabetes ${ }^{14-16}$ and, recently, an Australasian working party has similarly recommended the use of HbAlc for diagnostic purposes. ${ }^{17}$ The recommendation is that diabetes is diagnosed by an HbAlc level of $\geq 6.5 \%$ $(48 \mathrm{mmol} / \mathrm{mol})$. ADA also endorsed the use of HbAlc in the range of $\geq 5.7 \%$ and $<6.5 \% \quad(\geq 39$ and $<48 \mathrm{mmol} /$ mol)) for the diagnosis of prediabetes. ${ }^{15}$ This allows for the development of new approaches to the screening for diabetes. A US-based study showed that HbAlc could be used to detect undiagnosed diabetes in hospitalised patients. ${ }^{6}$ In a recent Australian study of hospitalised patients using a diagnostic HbA1c cut-off of $\geq 6.5 \%$, undiagnosed diabetes was found in $11 \% .^{18}$

A major contributor to cost in screening programmes is the organisation and collection of blood samples. In this study, we used blood samples already available to ACT Pathology (Canberra, Australian Capital Territory, Australia) from referral for unrelated tests to assess prevalence of undiagnosed diabetes using HbAlc. Three separate groups were assessed: community-based patients referred for pathology testing by family physicians (CB), patients attending only the emergency department (ED) and hospitalised inpatients (IP).

\section{METHODS}

\section{Ethical considerations}

This study was approved by the ACT Health Human Research Ethics Committee. Approval without obtaining participant consent was based on the recommendations of Section 2.3.6 of the National Statement on Ethical Conduct in Human Research (2007), particularly part b "the benefits of the research justify any risk or harm associated with not seeking consent", part c "it is impracticable to obtain consent" and part g "in case the results have significance for participants' welfare there is, where practicable, a plan for making information arising from the research available to them". ${ }^{19}$

\section{Participants}

ACT Pathology is a certified laboratory with the National Glycohemoglobin Standardisation Program (NGSP) and provides pathology testing services to acute hospital patients (IP and emergency) and community patients. HbAlc measurement requires a sample to be collected in an EDTA tube, and this is the same sample that is required for a full blood count (FBC). We used samples referred to the laboratory for an FBC for our screening study. The ACT Pathology Laboratory Information System (LIS) was used to search for consecutive FBC samples from April 2010 to January 2011. There were some breaks in collection due to research assistant unavailability. A total of 22396 FBC requests were identified and the pathology electronic history for the respective participants was exported into LabWizard (Pacific Knowledge Systems, Surry Hills, New South Wales, Australia). The participants were separated into three groups according to the collection site of the samples: CB, ED and IP (figure 1).

Samples were excluded if they were duplicate samples from the same participant, if the participant was $<18$ years of age, if the participant was pregnant, or if the participant was postsurgery or had had a transfusion. Other exclusion criteria were any requests for HbAlc testing in the previous 12 months, evidence of diabetes screening by a glucose tolerance test or a glucose load test in the previous 12 months, and a previous diagnosis of diabetes identified from within the LIS from clinical notes, results indicative of diabetes or requests for investigating diabetes. Samples from participants presenting to ED who had a record of any pathology testing in the previous 12 months were also excluded (figure 1).

\section{Sample collection and HbA1c assay}

Samples were collected after completion of the FBC analysis and stored at $-80^{\circ} \mathrm{C}$ prior to $\mathrm{HbAlc}$ testing. Samples that were not located or had insufficient volume or were visibly degraded were removed from the testing cohort (figure 1). HbA1c was measured in 4505 samples using a Biorad Variant II Turbo Analyser (Bio-Rad Laboratories Pty, Ltd, Hercules, California, USA). The interassay coefficient of variation based on the NGSP HbA1c \% values was $2.3 \%$ at an HbAlc of $5.15 \%$ and $1.7 \%$ at an HbAlc of $9.77 \%$. Samples were not stored for a period longer than 6 months prior to being tested.

\section{Diagnosis of unknown diabetes}

From the tested samples, a diagnosis of diabetes was made if the $\mathrm{HbAlc}$ was $\geq 6.5 \%$ (48 mmol $/ \mathrm{mol}$ ). To determine if this diagnosis was previously known or unknown for the respective individual, the hospital record (if available) was searched and the family practitioner was contacted (by phone) to determine the individual's history.

\section{Statistical analysis}

HbAlc data are duly reported in the traditional NGSP $\mathrm{HbAlc} \%$ format and the SI unit $\mathrm{mmol} / \mathrm{mol}$ as endorsed by the International Federation of Clinical Chemistry. The descriptive statistics used include the means $\pm \mathrm{SD}$, median, maximal and minimal as indicated.

An analysis of variance was conducted to investigate age and gender determinants of the measured HbA1c in the three patient groups. Age in years was included as a linear effect, rather than as specific age categories, because HbAlc was found to change in a smooth linear fashion with age. This linear effect was allowed to vary between men and women in the final model. More flexible non-linear age effects, and formulations that allowed differences in the age effect for the three patient groups, were examined, but neither was found to be supported by the data. The analysis was conducted in the R statistical software. ${ }^{20}$ 


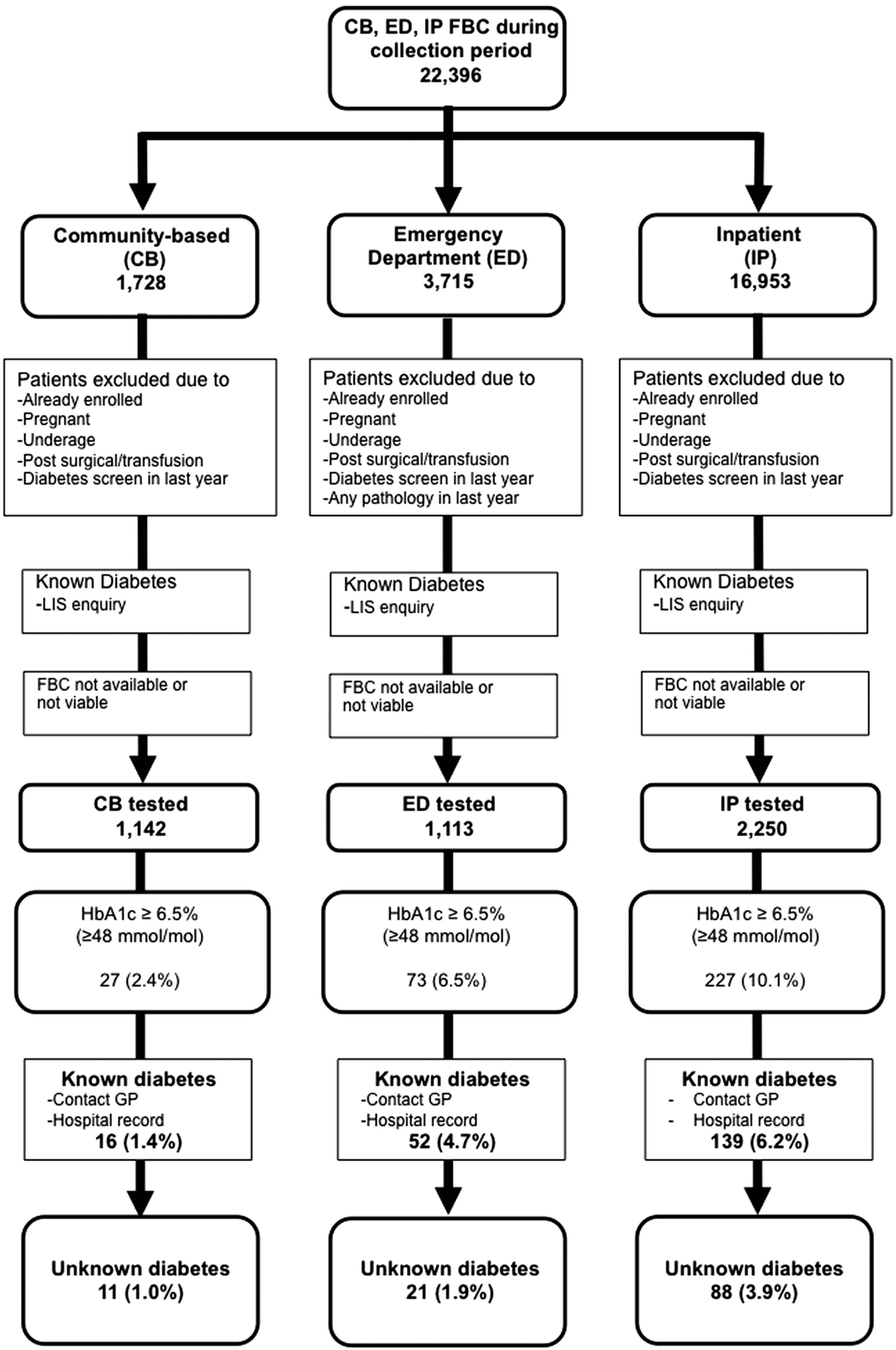

Figure 1 Flow diagram showing the process involved in selecting full blood count (FBC) samples for opportunistic glycated haemoglobin ( $\mathrm{HbA1c}$ ) testing and the overall testing results. Patients were divided into community-based (CB), emergency department (ED) and inpatient (IP) groups based on origin of sample collection. Samples were excluded from testing according to the reasons indicated (upper rectangular grey boxes). Of the patients tested, those found to have elevated $\mathrm{HbA1c} \geq 6.5 \%$ ( $\geq 48 \mathrm{mmol} / \mathrm{mol}$ ) and to have previously known diabetes were excluded (lower rectangular box). The number of patients found to have previously undiagnosed diabetes is shown in the lower rounded-edge boxes. LIS, laboratory inquiry system; GP, general practitioner. 


\section{RESULTS}

A total of 22396 samples suitable for HbAlc analysis were received in the study time interval. After excluding samples for the reasons listed above, HbAlc was measured in $1142 \mathrm{CB}, 1113 \mathrm{ED}$ and 2250 IP samples (figure 1). A total of $4505 \mathrm{HbAlc}$ tests were performed, of which 327 $(7.3 \%)$ had test readings of $\geq 6.5 \%(\geq 48 \mathrm{mmol} / \mathrm{mol})$, consistent with the diagnosis of diabetes. After examination of the hospital record and/or contacting the family practitioner, we had 120 cases (2.7\% of total tested) of previously unsuspected diabetes. Of the 120 new cases of diabetes, $11(1 \%)$ were CB participants, 21 (1.9\%) were from the ED group and $88(3.9 \%)$ were the hospital IP group (figure 1).

Analysis of the tested cohort (known diabetes patients removed) showed that the mean HbA1c levels were 5.4 $\pm 0.4 \% \quad(36 \pm 5 \mathrm{mmol} / \mathrm{mol}) \quad$ for $\mathrm{CB}, \quad 5.5 \pm 0.5 \% \quad(37$ $\pm 5 \mathrm{mmol} / \mathrm{mol})$ for $\mathrm{ED}$ and $5.6 \pm 0.5 \%(38 \pm 6 \mathrm{mmol} / \mathrm{mol})$ for IP participants (table 1). The CB and ED patients were, respectively, an average of 7.4 and 9.7 years younger than the IP patients (table 1 ). Considering that HbA1c increased linearly with age $(0.5 \%$ from ages 20 to $90 ; \mathrm{p}<0.001)$, the $\mathrm{HbA1c}$ results were adjusted for age difference between the groups. IP age-adjusted HbAlc was still found to be greater than CB HbAlc $(p<0.001)$. Age-adjusted HbAlc results for ED patients were not different from those for the other groups. Besides age, patient gender was also an important consideration, with women having $\mathrm{HbA1c}$ results $0.13 \%$ less than men $(\mathrm{p}<0.05)$. Also, the age-related increase in HbAlc is more pronounced for men than for women $(p<0.05)$. Of note, age, gender and group only explained $12 \%$ of the variability in $\mathrm{HbAlc}$ results.
Patients with a new diagnosis of diabetes were significantly older than the non-diabetic patients in each of the tested groups and were more likely to be from the ED and IP groups (tables 1 and 2). In fact, previously undiagnosed diabetes was not detected at all in the CB group less than 40 years of age compared with a rate of $5.8 \%$ detection in the IP group over the age of 54 (table 2).

ADA has classified patients with HbAlc levels in the range of $5.7-6.4 \%(39-47 \mathrm{mmol} / \mathrm{mol})$ as having prediabetes. ${ }^{15}$ Of the patients in our study, $24.8 \%, 28.7 \%$ and $39.5 \%$ of CB, ED and IP patients, respectively, had HbAlc levels in this range (table 2).

\section{DISCUSSION}

Diabetes mellitus is an ideal condition to screen for, as it fulfils all the principles of screening that need to be met according to WHO. ${ }^{21}$ The challenge is to perform regular screening of the population in a time-effective and cost-effective manner. Population-based surveys, including the AUSDIAB study in Australia, indicate that about $50 \%$ of patients with diabetes have not been diagnosed. ${ }^{3}$ In this study, we investigated whether opportunistic diabetes screening through measuring HbAlc in blood samples ordered for other reasons could assist in uncovering some of these cases of undiagnosed diabetes.

HbAlc levels were measured in samples from three separate populations: community-based participants being more likely to be relatively well and under continuing general practitioner care $(\mathrm{CB})$; participants who had attended only the emergency department in the last

\begin{tabular}{|c|c|c|c|}
\hline & Community-based $(n=1126)$ & Emergency $(n=1061)$ & Inpatient $(n=2114)$ \\
\hline \multicolumn{4}{|l|}{ Age (years) } \\
\hline Mean $( \pm S D)$ & $51.8( \pm 17.1)$ & $49.5( \pm 20.5)$ & $59.2( \pm 19.1)$ \\
\hline Median & 52 & 47 & 61 \\
\hline Range & 18-92 & $18-98$ & $18-97$ \\
\hline \multicolumn{4}{|l|}{$\mathrm{HbA1c}(\%) \dagger$} \\
\hline Mean $( \pm S D)$ & $5.4( \pm 0.4)$ & $5.5( \pm 0.5)$ & $5.6( \pm 0.5) \ddagger$ \\
\hline Median & 5.4 & 5.5 & 5.6 \\
\hline Range & $3.7-8.9$ & $4.0-10.3$ & $3.2-12.2$ \\
\hline \multicolumn{4}{|l|}{$\mathrm{HbA} 1 \mathrm{c}(\mathrm{mmol} / \mathrm{mol}) \dagger$} \\
\hline Mean $( \pm S D)$ & $36( \pm 5)$ & $37( \pm 5)$ & $38( \pm 6) \ddagger$ \\
\hline Median & 36 & 37 & 38 \\
\hline Range & $17-71$ & 20-89 & $11-110$ \\
\hline \multicolumn{4}{|c|}{ Mean $( \pm \mathrm{SD})$ of age (years) of patients with $\mathrm{HbA} 1 \mathrm{c} \%(\mathrm{mmol} / \mathrm{mol})$} \\
\hline$<5.7(<39)$ & $48.5( \pm 16.8)$ & $44.2( \pm 18.8)$ & $54.7( \pm 19.8)$ \\
\hline $5.7-5.9(39-41)$ & $60.7( \pm 13.6)$ & $59.9( \pm 18.9)$ & $63.4( \pm 17.8)$ \\
\hline $6.0-6.4(42-47)$ & $63.1( \pm 15.3)$ & $64.1( \pm 19.5)$ & $66.7( \pm 14.5)$ \\
\hline$\geq 6.5(\geq 48)$ & $59.5( \pm 10.2)$ & $65.0( \pm 18.1)$ & $67.7( \pm 15.6)$ \\
\hline
\end{tabular}


Table 2 Patients within the HbA1c categories according to age within the tested community-based, emergency department and inpatient groups ${ }^{\star}$

\begin{tabular}{|c|c|c|c|}
\hline & Community-based & Emergency & Inpatient \\
\hline \multicolumn{4}{|c|}{ Number [\%] patients with $\mathrm{HbA} 1 \mathrm{c} \%(\mathrm{mmol} / \mathrm{mol}) \dagger$} \\
\hline \multicolumn{4}{|c|}{ Age $<40$ years } \\
\hline$<5.7(<39)$ & 276 [92.9] & $333[88.1]$ & $305[80.5]$ \\
\hline $5.7-5.9(39-41)$ & $15[5.1]$ & $31[8.2]$ & $53[14.0]$ \\
\hline $6.0-6.4(42-47)$ & $6[2.0]$ & $12[3.2]$ & $16[4.2]$ \\
\hline$\geq 6.5(\geq 48)$ & $0[0.0]$ & $2[0.5]$ & 5 [1.3] \\
\hline Total & $297[100]$ & $378[100]$ & 379 [100] \\
\hline \multicolumn{4}{|c|}{ Age $\geq 40$ to $<55$ years } \\
\hline$<5.7(<39)$ & $245[79.0]$ & $203[72.2]$ & $290[63.5]$ \\
\hline $5.7-5.9(39-41)$ & $39[12.6]$ & $54[19.2]$ & $101[22.1]$ \\
\hline $6.0-6.4(42-47)$ & $23[7.4]$ & $21[7.5]$ & $57[12.5]$ \\
\hline$\geq 6.5(\geq 48)$ & $3[1.0]$ & $3[1.1]$ & 9 [2.0] \\
\hline Total & $310[100]$ & $281[100]$ & 457 [100] \\
\hline \multicolumn{4}{|l|}{ Age 55 and above } \\
\hline$<5.7(<39)$ & 317 [61.1] & $200[49.8]$ & $595[46.6]$ \\
\hline $5.7-5.9(39-41)$ & $135[26.0]$ & $111[27.6]$ & 345 [27.0] \\
\hline $6.0-6.4(42-47)$ & $59[11.4]$ & 75 [18.7] & 264 [20.7] \\
\hline$\geq 6.5(\geq 48)$ & $8[1.5]$ & $16[4.0]$ & $74[5.8]$ \\
\hline Total & $519[100]$ & $402[100]$ & 1278 [100] \\
\hline \multicolumn{4}{|l|}{ All patients } \\
\hline$<5.7(<39)$ & $838[74.4]$ & 736 [69.3] & 1190 [56.3] \\
\hline $5.7-5.9(39-41)$ & 189 [16.5] & $196[18.5]$ & 499 [23.6] \\
\hline $6.0-6.4(42-47)$ & $88[7.8]$ & $108[10.2]$ & $337[15.9]$ \\
\hline$\geq 6.5(\geq 48)$ & $11[1.0]$ & 21 [2.0] & 88 [4.2] \\
\hline Total & 1126 [100] & $1061[10]$ & 2114 [100] \\
\hline
\end{tabular}

12 months (as far as our records showed) (ED); and hospitalised participants reflecting a group of sicker individuals (IP). Efforts were made to eliminate testing samples in participants who were likely to have already been diagnosed with diabetes or who were likely to have been screened for diabetes within the previous 12 months. It was anticipated that objective evidence of undiagnosed diabetes mellitus might be quite different between these three groups.

In the participants eventually tested, the rates of previously undiagnosed diabetes were $1 \%, 1.9 \%$ and $3.9 \%$ in the CB, ED and IP groups, respectively. Despite efforts to exclude testing samples from patients already with a diagnosis of diabetes, $1.4 \%, 4.7 \%$ and $6.2 \%$ of the patients in the three respective groups did have a previous diagnosis. Age was a major factor in determining risk. Patients $<40$ years of age had rates of previously unknown diabetes of $0 \%, 0.5 \%$ and $1.3 \%$ in the $\mathrm{CB}, \mathrm{ED}$ and IP groups, respectively, compared with $1.5 \%, 4 \%$ and $5.8 \%$ in patients $>54$ years of age.

The family doctors of all the patients newly diagnosed with diabetes in this study were notified such that confirmation of the diagnosis could occur and appropriate care could be initiated. The action taken by the family doctors, however, was not within the scope of this study. Considering that $\mathrm{WHO}$ and ADA state that a single
HbA1c $\geq 6.5 \%(48 \mathrm{mmol} / \mathrm{mol})$ is diagnostic of diabetes, false-positive diagnoses should occur rarely. Therefore, this method of screening should have a high-positive predictive value.

Previous studies have also investigated the prevalence of undiagnosed diabetes in a hospital setting. Wexler et at from the USA found a comparable $5 \%$ of unsuspected diabetes in hospitalised patients using the cut-off $>6.5 \%$ ( $>48 \mathrm{mmol} / \mathrm{mol})$. An Australian study from Adelaide by Valentine et $a l^{17}$ found $11.1 \%$ of unsuspected diabetes, which is much higher than our results. However, their methodology only tested HbA1c on those with bloods taken at admission with a random plasma glucose $>5.5 \mathrm{mmol} / \mathrm{L}$, so it is not truly representative of hospital inpatients, rather representative of a group with an expected higher positive rate of diabetes. This study also was reliant on correct coding for diabetes on discharge in order to exclude previously known diabetes. For the current study, efforts to exclude previous diabetes were much more rigorous with careful review of the hospital record, if available, and phone calls to the patients' family doctors.

The current study also differed from the previous studies in that $\mathrm{CB}$ and $\mathrm{ED}$ patients not admitted to the hospital were included. The rate of unknown diabetes in the $\mathrm{CB}$ group was quite low at $1 \%$. This is much lower than 
the rate of undiagnosed diabetes in the communitybased AUSDIAB cohort, but a proportion of the AUSDIAB cohort would not have been engaged in regular medical care. ${ }^{3}$ General practitioners predominantly care for the $\mathrm{CB}$ patients of the current study such that the low level of unsuspected diabetes in these patients may be indicative of a high level of awareness of diabetes and screening by them within the ACT region. For this reason, opportunistic pathology-based diabetes screening in this group and in this locale may not be as rewarding as in the other groups.

The ED group had twice the rate of unknown diabetes compared with the CB group at $1.9 \%$. An opportunistic approach to diabetes screening may be much more relevant to the ED group, as a higher proportion are quite likely to not be engaged with routine care with a family doctor. This group is also likely to include frequent attendees to hospital with chronic illness, although many of these patients would have been excluded because of a record of other pathology testing in the preceding 12 months. As expected, the IP group had the highest rate of unknown diabetes at $3.9 \%$.

An important contributor to any screening programme cost is sample collection and data entry. The procedure we describe removes these costs. In an opportunistic screening, costs could also be reduced by enhancedcomputer systems to identify samples to be tested and inclusion of the result in the routine pathology reporting to the patients' treating doctors. It has recently been noted that screening for diabetes in the UK did not reduce mortality at 10 years. $^{22} 23$ However, intensive treatment following diagnosis reduces complications and also reduces mortality over a longer period. ${ }^{10}$

In conclusion, within this Australian setting, opportunistic diabetes screening using $\mathrm{HbAlc}$ on FBC samples collected for other purposes is possible and costeffective. Patients presenting to the emergency department or admitted to hospital and being older than 54 years of age are most likely to have previously unknown diabetes. This method of diabetes screening warrants further consideration.

Acknowledgements We would like to thank Dr Brent Henderson of CSIRO Computational Informatics for his statistical advice and Professor Jim Butler of Australian National University for his advice relating to health economics.

Contributors AJS and RK collected and tabulated the data; JLK collected and tabulated the data and contributed to the writing of the paper; EKS helped plan and implement the study; CJN helped plan the study, reviewed the data and helped write the paper, JDW and JMP helped plan the study and reviewed the data; and PEH helped plan the study, reviewed the data and helped write the paper. He is the guarantor of the study. All the authors reviewed the final version of the manuscript.

Funding This project was supported by a grant from the Canberra Hospital Private Practice Trust Fund.

Competing interests None.

Ethics approval ACT Health Human Research Ethics Committee.

Provenance and peer review Not commissioned; externally peer reviewed.

Data sharing statement No additional data are available.
Open Access This is an Open Access article distributed in accordance with the Creative Commons Attribution Non Commercial (CC BY-NC 3.0) license, which permits others to distribute, remix, adapt, build upon this work noncommercially, and license their derivative works on different terms, provided the original work is properly cited and the use is non-commercial. See: http:// creativecommons.org/licenses/by-nc/3.0/

\section{REFERENCES}

1. Nolan CJ, Damm P, Prentki M. Type 2 diabetes across generations: from pathophysiology to prevention and management. Lancet 2011;378:169-81

2. Shaw JE, Sicree RA, Zimmet PZ. Global estimates of the prevalence of diabetes for 2010 and 2030. Diabetes Res Clin Pract 2010;87:4-14.

3. Dunstan DW, Zimmet PZ, Welborn TA, et al. The rising prevalence of diabetes and impaired glucose tolerance: the Australian Diabetes, Obesity and Lifestyle Study. Diabetes Care 2002;25:829-34.

4. Harris MI, Klein R, Welborn TA, et al. Onset of NIDDM occurs at least 4-7 yr before clinical diagnosis. Diabetes Care 1992;15:815-19.

5. UK Prospective Diabetes Study 6. Complications in newly diagnosed type 2 diabetic patients and their association with different clinical and biochemical risk factors. Diabetes Res 1990;13:1-11.

6. Wexler DJ, Nathan DM, Grant RW, et al. Prevalence of elevated hemoglobin A1c among patients admitted to the hospital without a diagnosis of diabetes. J Clin Endocrinol Metab 2008;93:4238-44.

7. Colagiuri S, Lee CM, Wong TY, et al. Glycemic thresholds for diabetes-specific retinopathy: implications for diagnostic criteria for diabetes. Diabetes Care 2011;34:145-50.

8. Balkau B, Shipley M, Jarrett RJ, et al. High blood glucose concentration is a risk factor for mortality in middle-aged nondiabetic men. 20-year follow-up in the Whitehall Study, the Paris Prospective Study, and the Helsinki Policemen Study. Diabetes Care 1998;21:360-7.

9. Stratton IM, Adler AI, Neil HA, et al. Association of glycaemia with macrovascular and microvascular complications of type 2 diabetes (UKPDS 35): prospective observational study. BMJ 2000;321:405-12.

10. Holman RR, Paul SK, Bethel MA, et al. 10-year follow-up of intensive glucose control in type 2 diabetes. $N$ Engl J Med 2008;359:1577-89.

11. UK Prospective Diabetes Study Group. Intensive blood-glucose control with sulphonylureas or insulin compared with conventional treatment and risk of complications in patients with type 2 diabetes (UKPDS 33). UK Prospective Diabetes Study (UKPDS) Group. Lancet 1998;352:837-53.

12. Goyder E, Irwig L, Payne N. Should we screen for type 2 diabetes? No. BMJ 2012;345:e4516.

13. Khunti K, Davies M. Should we screen for type 2 diabetes: yes. BMJ 2012;345:e4514.

14. World Health Organization. Use of glycated haemoglobin (HbA1c) in the diagnosis of diabetes mellitus. Geneva, Switzerland: WHO Press, 2011.

15. American Diabetes Association. Diagnosis and classification of diabetes mellitus. Diabetes Care 2010;33(Suppl 1):S62-9.

16. John WG. Use of $\mathrm{HbA} 1 \mathrm{c}$ in the diagnosis of diabetes mellitus in the UK. The implementation of World Health Organization guidance 2011. Diabet Med 2012;29:1350-7.

17. D'Emden MC, Shaw JE, Colman PG, et al. The role of HbA1c in the diagnosis of diabetes mellitus in Australia. Med $J$ Aust 2012;197:220-1.

18. Valentine NA, Alhawassi TM, Roberts GW, et al. Detecting undiagnosed diabetes using glycated haemoglobin: an automated screening test in hospitalised patients. Med J Aust 2011;194:160-4.

19. National Health and Medical Research Council. National Statement on Ethical Conduct in Human Research. 2007. http://www.nhmrc. gov.au/_files_nhmrc/publications/attachments/e72.pdf

20. R Development Core Team. R: a language and environment for statistical computing. Vienna, Austria: R Foundation for Statistical Computing, 2008. ISBN: 3-900051-07-0. http://www.R-project.org

21. Wilson JMG, Junger G. Principles and practice of screening for disease. Public Health Papers No. 34. Geneva: World Health Organization, 1968 http://whqlibdoc.who.int/php/WHO_PHP_34.pdf.

22. Simmons RK, Echouffo-Tcheugui JB, Sharp SJ, et al. Screening for type 2 diabetes and population mortality over 10 years (ADDITION-Cambridge): a cluster-randomised controlled trial. Lancet 2012;380:1741-8.

23. Hawkes N. Screening for type 2 diabetes doesn't affect mortality at 10 years. BMJ 2012;345:e6687. 